\title{
ARQUITETURA DA INFORMAÇÃO PARA PROCESSOS DE NEGOCIO: um caminho para a governança de dados
}

\section{INFORMATION ARCHITECTURE FOR BUSINESS PROCESS: a way to data governance}

\author{
Mariana Baptista Brandt ${ }^{1}$ \\ Silvana Aparecida Borsetti Gregorio Vidotti ${ }^{2}$
}

\begin{abstract}
RESUMO
As organizações produzem e consomem dados e informações cotidianamente em seus processos de negócio. Os dados são produzidos, alimentados, consultados, analisados e transformados ao longo das atividades e operações, e se constituem em uma fonte de informação essencial para o desenvolvimento das instituições. Os processos de negócios estão presentes em todas as atividades das organizações, mesmo que não formalizados. As instituições em seus diversos setores, como financeiro, recursos humanos, serviços gerais, diretorias e informática, possuem rotinas, processos e tarefas que são denominados processos de negócio. Essa investigação pauta-se no seguinte questionamento: como gerir esses dados adequadamente em um processo de negócios para a governança de dados? Para que a governança seja implementada, é necessária uma estrutura na qual os dados sejam mapeados, organizados, documentados e geridos. Nesse contexto apresenta-se a Arquitetura da Informação para Processos de Negócio como uma metodologia de Arquitetura da Informação que parte do processo de negócio para obter as informações mais importantes dos processos e representá-las, por meio de metadados de negócio, os quais serão registrados e descritos por atributos, configurando requisitos de informação. Desse modo, observa-se que a Arquitetura da Informação para Processos de Negócio deve ser o ponto de partida para a construção dos sistemas de informação que dão suporte ao negócio. Assim, fornecem insumos para a gestão dos dados e informações e para a governança de dados, por meio de seus entregáveis.
\end{abstract}

Palavras-chave: Arquitetura da Informação. Processos de Negócio. Arquitetura da Informação para Processos de Negócio. Metadados de Negócio.

\section{ABSTRACT}

Organizations produce and consume data and information daily in their business processes. Data is produced, fed, consulted, analyzed, and transformed throughout the activities and operations, and is an essential source of information for the development of institutions. The business processes are present in all the activities of the organizations, even if not formalized. Institutions in their various sectors such as finance, human resources, general services, management, and information technology have routines, processes, and tasks that are called business processes. This investigation is based on the following question: how to manage this data properly in a business process for data governance? For governance to be implemented it is necessary a structure in which the data are mapped, organized, documented, and managed. In this context, Information Architecture for Business Processes is presented as an Information Architecture methodology that starts from the business process to obtain the most important information of the processes and represents it, through business metadata, which will be registered and described by attributes, configuring information requirements. Thus, it is observed that Information Architecture for Business Processes must be the starting point for the construction of the information systems that support the business to provide inputs for the management of data and information, and data governance, through its deliverables.

Keywords: Information Architecture. Business Processes. Information Architecture for Business Processes. Business Metadata.

Artigo submetido em 19/11/2020 e aceito para publicação em 06/12/2020

1 Doutora em Ciência da Informação. Universidade Estadual Paulista Júlio de Mesquita Filho, Brasil. Analista Legislativo do Centro de Documentação e Informação. Câmara dos Deputados, Brasil. ORCID: https://orcid.org/0000-0001-8119-7527. Email: mariana. brandt@unesp.br

2 Docente do Departamento e do Programa de Pós-Graduação em Ciência da Informação Universidade Estadual Paulista Júlio de Mesquita Filho, Brasil. ORCID: https://orcid.org/0000-0002-4216-0374. Email: silvana.vidotti@unesp.br 


\section{INTRODUÇÃO}

As organizações produzem e consomem informações a todo momento em seus processos de negócio. Dados são alimentados, consultados, analisados e transformados ao longo das atividades e operações cotidianas das empresas. Grande parte desses dados constitui uma fonte de informação essencial para o desenvolvimento das instituições e, para que esses dados sejam geridos adequadamente, se faz necessária a implementação de um processo de governança de dados. Essa governança está relacionada aos mecanismos desenvolvidos pelas instituições para tomada de decisão e definição de autoridade para assuntos relacionados a dados (DGl, c2017).

Para que a governança seja implementada, as instituições precisam que as estruturas que lidam com os dados sejam mapeadas, organizadas, documentadas e geridas, o que pode ser realizado por meio de práticas da Arquitetura da Informação (Al). A Arquitetura da Informação para Processos de Negócio (AIPN) é uma metodologia de Al que parte do processo de negócio para obter as informações mais importantes dos processos e representá-las, por meio de metadados de negócio que serão registrados e descritos por atributos, configurando requisitos de informação. Tais requisitos devem ser utilizados para o desenvolvimento de sistemas de informação que atendam, de forma efetiva, as áreas de negócio e permitam a realização da gestão de dados e informações, bem como a governança de dados.

0 objetivo deste trabalho é apontar como a metodologia de Al para Processos de Negócios se mostra útil e efetiva para a estruturação da informação corporativa e como isso pode viabilizar e facilitar os processos de governança de dados. Para isso, a seção 2 realiza uma breve revisão bibliográfica sobre governança de dados. Já a seção 3 enfatizou os temas de processos de negócio e metadados de negócio, considerados conceitos fundamentais para a compreensão da AIPN. A seção final discute a relação entre os conceitos anteriores com a metodologia de AIPN e como esta oferece suporte técnico e metodológico para o estabelecimento dos processos de governança de dados, informações e metadados da instituição, por meio de seus entregáveis de Al.

\section{GOVERNANÇA DE DADOS}

A governança é uma estrutura da alta administração responsável por definir papéis, responsabilidade e autoridade em relação à determinada área da instituição. A governança está 
relacionada ao direcionamento estratégico, à prestação de contas e transparência nos processos de auditoria e avaliação. A governança gerencia os riscos e conflitos, envolve as partes interessadas e supervisiona a gestão. Os processos de governança são complementados pelos processos de gestão, mas possuem níveis diferentes de atuação:

A governança e a gestão são funções complementares; enquanto a primeira direciona, monitora e avalia a atuação da gestão para garantir com que as estratégias sejam implementadas; a segunda planeja, executa, controla e age em busca do alcance dos objetivos estabelecidos (TRIBUNAL DE CONTAS DA UNIÃO, 2019).

Dentre as diversas áreas passíveis de implementação de processos de governança está a governança de dados, definida como:

[...] conjunto de políticas, processos, pessoas e tecnologias que visam a estruturar e administrar os ativos de informação, com o objetivo de aprimorar a eficiência dos processos de gestão e da qualidade dos dados, a fim de promover eficiência operacional, bem como garantir a confiabilidade das informações que suportam a tomada de decisão. (BRASIL, 2016A)

Para governança da informação, encontramos a seguinte definição:

Especificação dos direitos de decisão e de um quadro de responsabilidades para incentivar a implementação de boas práticas na criação, armazenamento, uso, avaliação e arquivamento de informação. Inclui os processos, responsabilidades e métricas que garantem o uso eficiente da informação para permitir que uma organização atinja seus objetivos. (GARTNER, 2018, tradução nossa)

Neste trabalho, não se faz necessária a distinção entre governança de dados e governança de informações, sendo termos intercambiáveis referentes à diferentes estados de processamento de conteúdo (dado/informação). Para Barata (2015), a governança de dados é responsável pelo controle e gerenciamento de dados da organização e pela transformação dos dados em informações. 0 escopo da governança de dados é amplo e pode ter foco em diversas etapas do ciclo de vida dos dados, 0 que pode variar conforme a instituição (BARATA, 2015; ENAP, 2019). A governança de dados tem por objetivo a definição e implementação de estratégias de dados, políticas, normas, padrões, processos e métricas; patrocínio e definição da gestão de dados, implementação da gestão de riscos relacionados ao compartilhamento dos dados e a promoção valor dos dados como ativo estratégico na instituição (ENAP, 2019).

Segundo a ENAP (2019), “a Governança de Dados também atua como uma visão mais apurada sobre os dados estratégicos da organização, definindo e analisando os processos que produzem e se abastecem desses dados". Com a implementação da governança de dados, os dados gerados nos processos devem estar disponíveis a quem necessitar e o seu pronto acesso deve ser assegurado. 
Além disso, a governança de dados objetiva garantir que os dados sejam seguros, tenham qualidade e possam ser auditados (ESPINDOLA et al, 2018). A governança, por meio da atribuição de papeis de autoridade de dados e responsabilização de seus agentes, atua diretamente na melhoria da qualidade dos dados, já que:

Garantir que os dados sejam de alta qualidade é essencial para seu gerenciamento. Se os dados não atenderem às necessidades de seus consumidores - se não forem "adequados ao objetivo" -, então o esforço para coletar, armazenar, proteger e permitir o acesso a eles é desperdiçado (ENAP, 2019).

Como exemplo de papeis de autoridade de dados estão a Unidade Curadoria de Informação e o Agente de Curadoria, no exemplo da Governança da Informação proposta pelo Banco Central. Estas instâncias possuem como atribuições:

I - definir e manter:

a) as regras de retenção e de descarte das informações;

b) os valores de referência para os dados;

c) os requisitos, as regras de negócio e as métricas para a gestão da qualidade de dados;

d) as regras de acesso às informações, conforme os respectivos critérios de segurança e classificação;

II - monitorar e controlar a qualidade dos dados;

III - identificar e promover a resolução de eventuais problemas nas informações;

IV - prover auxílio em relação ao acesso e à análise das informações;

$\mathrm{V}$ - assegurar o devido atendimento às consultas dos interessados, observando as restrições cabíveis;

$\mathrm{VI}$ - no caso de informações oriundas do SFN:

a) propor ao CGI documentos de dados e normativos para a criação e a atualização de captações de informações relacionadas à base de dados;

b) manter atualizadas as informações correspondentes no Catálogo de Recepção de Documentos e Informações;

c) monitorar as captações de informações relativas à base de dados, gerando os registros necessários à auditoria de observância;

d) observar os procedimentos e adotar as medidas previstas no Regulamento de Auditoria de Observância;

VII - comunicar mudanças e problemas aos usuários das informações; e

VIII - manter atualizada a documentação no Catálogo de Informações. (BRASIL, 2016).

Além de prezar pela qualidade dos dados, a governança está relacionada também ao papel de conformidade legal, já que as empresas estão sujeitas à legislação e, com a atual presença da tecnologia, há várias normas relacionadas aos dados e informações corporativos. 0 exemplo mais recente é o da Lei Geral de Proteção de Dados (LGPD), Lei n. 13.709 de 2018³, que entrou em vigor em 18 de setembro de 2020 e tem seus efeitos válidos em todas as instituições que coletam e disseminam dados pessoais. A referida Lei prevê que todas as empresas que coletam e armazenam dados pessoais

3 Disponível em: https://www2.camara.leg.br/legin/fed/lei/2018/lei-13709-14-agosto-2018-787077-publicacaooriginal-156212-pl.html 
tenham procedimentos padrão para o tratamento dos dados: "Essa Lei versa sobre o tratamento de dados pessoais, dispostos em meio físico ou digital, feito por pessoa física ou jurídica de direito público ou privado e engloba um amplo conjunto de operações efetuadas em meios manuais ou digitais". (BRASIL, 2020). Assim, a legislação determina uma série de práticas que devem ser efetuadas em relação aos dados pessoais, denominado como tratamento de dados:

Considera-se "tratamento de dados" qualquer atividade que utilize um dado pessoal na execução da sua operação, como, por exemplo: coleta, produção, recepção, classificação, utilização, acesso, reprodução, transmissão, distribuição, processamento, arquivamento, armazenamento, eliminação, avaliação ou controle da informação, modificação, comunicação, transferência, difusão ou extração. (BRASIL, 2020).

A governança de dados implementada possibilita a operacionalização desse tratamento de dado determinado pela LGPD: "Atender a uma legislação sempre em evolução requer processos aprimorados de governança de dados" (ENAP, 2019). Os dados que devem ser tratados nos procedimentos de gestão e governança permeiam as atividades do dia a dia das empresas nos processos de negócio. Sua relação com dados e informações de metadados serão discutidos na seção a seguir.

\section{PROCESSOS DE NEGÓCIO}

Os processos estão presentes em todas as atividades das organizações, mesmo que não formalizados. As instituições, nos seus diversos setores, como, por exemplo, financeiro, recursos humanos, serviços gerais, diretorias, informática e todos os demais. Ou seja, todas as áreas de negócio de uma organização que possuem suas rotinas, processos e tarefas são os chamados processos de negócio ou processos de trabalho.

Baldam et al. (2007, p. 19) definem processo como "[...] um encadeamento de atividades executadas dentro de uma companhia ou organização, que transformam as entradas em saídas". Segundo Gonçalves (2000, p. 7), "não existe um produto ou um serviço oferecido por uma empresa sem um processo empresarial”. Assim, para a área de Administração processos podem ser entendidos como atividades ou conjuntos de atividades que adicionam valor a insumos e geram produtos para clientes (GONÇALVES, 2000; DAVENPORT, BEERS, 1995; BALDAM et al, 2007). Esses insumos, segundo Gonçalves (2000, p.7), "[...] podem ser materiais, equipamentos e outros bens tangíveis -, mas também podem ser informações e conhecimento".

Os processos de uma instituição precisam ser descritos e documentados, e a abordagem utilizada para esta atividade é conhecida como modelagem de processos de negócio. A modelagem 
de processos de negócio é necessária para as organizações que utilizam Gestão por Processos, inserindo-se no modelo BPM - Business Process Management, ou seja, Gerenciamento de Processos de Negócio.

A modelagem de processos é uma área importante para a Arquitetura da Informação e para processos de negócio, pois traz os componentes dos processos, das atividades e das tarefas, como meios de se obter as informações importantes para os processos. Segundo Choo (2006, p. 27):

A informação é um componente intrínseco de quase tudo que uma organização faz. Sem uma clara compreensão dos processos organizacionais e humanos pelos quais a informação se transforma em percepção, conhecimento e ação, as empresas não são capazes de perceber a importância das suas fontes e tecnologias da informação.

A modelagem de processos também é considerada indispensável para a implementação da Governança de Dados (FORSOS, 2018).

\begin{abstract}
Para escolher e implementar o sistema de informação correto de forma efetiva e eficiente, deve-se saber - em cada detalhe - todos os processos que irá impactar, como irá impactar, quem precisa ser envolvido e quando. Essas questões soam familiar? Devem soar, pois são as mesmas que perguntamos em governança de dados. Envolve análise de impacto, responsabilidade de posse e prestação de contas, controle e rastreabilidade - tudo que um processo de negócio efetivamente gerenciado e documentado permite. (FORSOS, 2018, não paginado)
\end{abstract}

Além disso, os sistemas de informação que dão suporte às atividades das áreas de negócio representam, muitas vezes, a automação dos processos de negócio. E a documentação desses processos e de suas informações são importantes para o desenvolvimento de soluções tecnológicas que atendam ao negócio de forma efetiva: "A modelagem de sistemas baseada em modelagem do estado futuro de processos de trabalho otimizados passou a ser considerada opção para construir sistemas mais aderentes às necessidades dos negócios e dos usuários”. (MIRANDA, 2010. p. 101).

Assim, os processos de negócio, por meio das informações do negócio, fornecem insumos para as atividades de Arquitetura da Informação, desenvolvimento de sistemas de informação e para a governança de dados. A seguir, trataremos dos metadados de negócio que são estruturas de representação das informações do negócio.

\title{
3.1 Metadados de Negócio
}

Metadados são estruturas de representação utilizadas para descrever recursos e objetos informacionais. Os metadados podem representar informações nos diversos níveis ou granularidades, 
descrevendo dados básicos desde documentos completos até informações das atividades de processos de trabalho. Um tipo de metadado utilizado pela comunidade de Gestão de Dados, Ciência da Computação, Arquitetura Corporativa, Inteligência de Negócio e áreas correlatas é o chamado Business Metadata ou Metadado de Negócio.

As informações de uma instituição costumam ser armazenadas em sistemas de informação, automatizados ou não, e fazem parte dos processos de negócio da instituição. Muitas dessas informações constituem os metadados de negócio. Segundo Inmon, O'Neil e Fryman (2008, p.12, tradução nossa), os metadados de negócio são "os metadados que são úteis para os gestores de negócio na condução do dia a dia de seu negócio". Assim, metadados de negócio podem ser entendidos como unidades básicas que estruturam os dados do negócio.

Figura 1 - Exemplo de metadados de negócio e seus dados

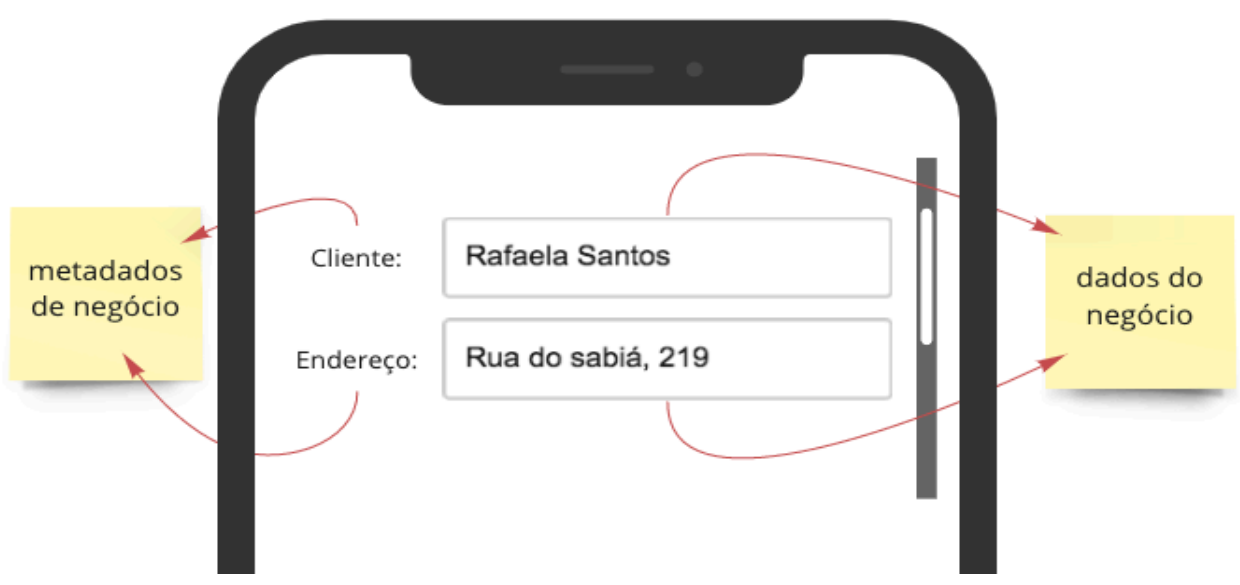

Fonte: Autoria própria

Os metadados de negócio precisam ser mapeados, registrados e gerenciados para que possam ser utilizados de modo uniforme e consistente nos diversos processos de negócio da instituição. Assim, é importante que se formalize uma instância de gestão de metadados de negócio para que os dados comportados por esses metadados também sejam geridos e estejam em conformidade com a governança de dados.

No contexto da Arquitetura da Informação para Processos de Negócio, os metadados de negócio identificam e descrevem os requisitos para os dados do negócio. Eles fornecem definição do significado do dado e indicam seus gestores, sua forma de acesso, o formato, possíveis valores do dado, a fonte 
ou origem do dado, e outras características que forem necessárias conforme o processo de negócio e a instituição. Essas definições são a base para a gestão dos metadados de negócio que, por sua vez, determinam as características dos dados do negócio. Também indicam as instâncias responsáveis por sua gestão, alimentação, atualização, completude e demais atributos que possam contribuir para a qualidade dos dados da organização. Assim, os metadados de negócio são considerados a unidade básica essencial da Arquitetura da Informação para processos de negócio, a qual será discutida na seção 4.

\section{ARQUITETURA DA INFORMAÇÃO COMO SUPORTE À GOVERNANÇA DE DADOS}

A Arquitetura da Informação para Processos de Negócio é uma metodologia de Arquitetura da Informação que permite organizar, representar e apresentar as informações nas empresas e organizações de todos os tipos em seus processos de trabalho, sistemas de informação e outros ambientes digitais de informação. A metodologia de Arquitetura da Informação é construída com base nos processos de trabalho de uma organização utilizando métodos e práticas da Ciência da Informação. Integra processos de trabalho e sistemas de informação por meio de dados e informações do negócio, o que possibilita a gestão da informação institucional e propicia condições para a governança de dados (BRANDT, 2020)

Nesta metodologia, parte-se do processo de negócio para identificar as informações do negócio e representá-las por meio de metadados de negócio, como visto na seção 3. Os metadados de negócio são registrados e descritos com atributos necessários para sua gestão: nome, descrição, forma de acesso, gestor do metadados, gestor do dado, entre outros que sejam necessários conforme o processo de negócio e a instituição. Esses atributos devem ser definidos conforme a necessidade e se tornam requisitos de informação que devem ser documentados para serem utilizados na construção dos sistemas de informação, na gestão das informações do negócio e também para a governança de dados. Entre os atributos, há os relacionados aos papeis e responsabilidades para cada metadado de negócio e para os dados que alimentam os metadados nos sistemas de informação. Assim, propõem-se um modelo de Al que representa uma visão completa da estrutura processo - dados/ informações - sistema, com os relacionamentos entre os elementos, como ilustrado na Figura 2 a seguir. 
Figura 2 - Elementos dos processos de negócio

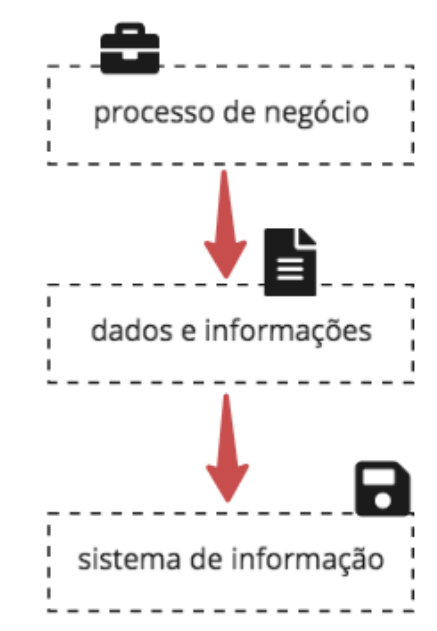

Fonte: Autoria própria

A aplicação da metodologia de Arquitetura da Informação para Processos de Negócio gera uma documentação importante para outras etapas, conforme citado anteriormente, denominada de entregáveis. "Em síntese, os entregáveis da Al são instrumentos concretos que possibilitam os Arquitetos da Informação externalizarem de maneira formal os resultados de seu trabalho acerca da construção de um espaço informacional." (DIAS; VID0TTI, 2011, p. 78). A seção a seguir aborda as etapas da metodologia de Arquitetura da Informação para Processos de Negócio e seus entregáveis, destacando os mais diretamente relacionados à governança de dados.

\subsection{Etapas da Arquitetura da Informação para Processos de Negócio e seus Entregáveis}

A Arquitetura da Informação para Processos de Negócio gera entregáveis de Al, os quais são documentos que materializam e comunicam as definições da Arquitetura da Informação e devem ser utilizados para o desenvolvimento dos sistemas de informação, a gestão da informação, e a governança de dados. A metodologia começa pela etapa de identificação das informações dos processos de negócio, com base no diagrama de processo de negócio. A cada etapa do processo são identificados documentos, sistemas de informação e quaisquer outros registros informacionais que possam ocorrer em cada atividade. Esses registros são a fonte dos dados do processo, ou seja, onde eles se originam (BRANDT, 2020). Assim, é possível mapear um dos principais elementos para a governança de dados, que é a origem ou proveniência dos dados na instituição. 
Figura 3 - Mapa das informações do processo

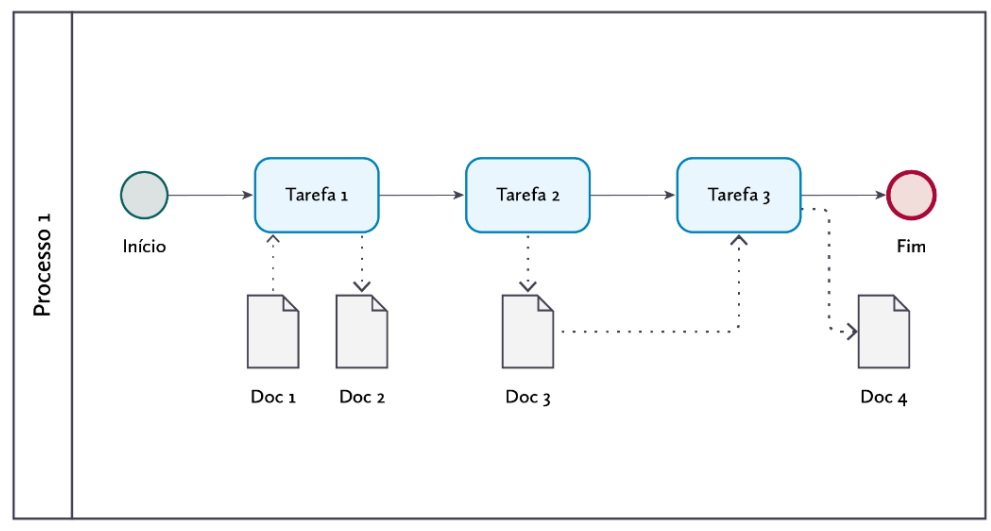

Fonte: BRANDT (2020, p. 70)

Para cada um desses registros são identificadas as informações importantes do negócio que podem ser estruturadas e representadas pelos metadados de negócio. Essas informações, registradas e descritas, compõem um documento chamado matriz de metadados, que pode ser visto como um documento de requisitos informacionais, ou seja, requisitos para a estruturação e gestão das informações do sistema. Para cada metadado de negócio é informado: o que ele significa; em qual processo de negócio aparece; qual a área de negócio gestora do dado; quem é responsável pela alimentação do dado no sistema; como o metadado deve ser representado no sistema, com suas restrições, regras de negócio, domínio de valores; entre vários outros atributos que se façam necessários. Esses atributos podem variar de acordo com os diferentes processos e áreas de negócio, como mencionado anteriormente. 0 resultado dessa descrição para cada metadado de negócio é como uma "ficha catalográfica" ou uma representação, conforme ilustra a Figura 4:

Figura 4 - Descrição de metadado de negócio

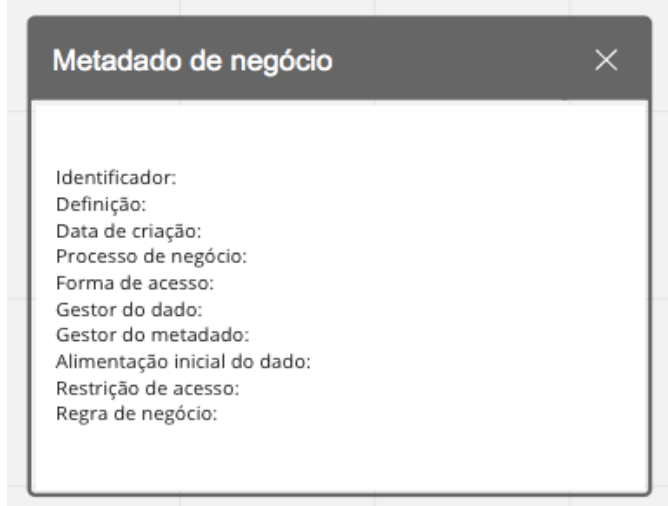

Fonte: Autoria própria 
Ao fazer a descrição de todos os metadados de negócio identificados e compilá-los em uma tabela, obtêm-se a Mariz de metadados, o segundo entregável de Al nesta metodologia para processos de negócio.

Quadro 1 - Matriz de metadados

\begin{tabular}{|c|c|c|c|c|c|c|c|c|c|}
\hline $\begin{array}{c}\text { Identifi- } \\
\text { cador }\end{array}$ & $\begin{array}{c}\text { Defini- } \\
\text { ção }\end{array}$ & $\begin{array}{c}\text { Data de } \\
\text { criação }\end{array}$ & $\begin{array}{c}\text { Processo de } \\
\text { Negócio }\end{array}$ & $\begin{array}{c}\text { Forma } \\
\text { de } \\
\text { Acesso }\end{array}$ & $\begin{array}{c}\text { Gestor } \\
\text { do dado }\end{array}$ & $\begin{array}{c}\text { Gestor do } \\
\text { metadado }\end{array}$ & $\begin{array}{c}\text { Alimenta- } \\
\text { ção inicial } \\
\text { do dado }\end{array}$ & $\begin{array}{c}\text { Restrição } \\
\text { de acesso }\end{array}$ & $\begin{array}{c}\text { Regra } \\
\text { de } \\
\text { negócio }\end{array}$ \\
\hline & & & & & & & & & \\
\hline & & & & & & & & & \\
\hline & & & & & & & & & \\
\hline & & & & & & & & & \\
\hline
\end{tabular}

Fonte: Autoria própria

A matriz de metadados deve conter uma espécie de manual de instruções para o preenchimento dos dados de maneira que garanta a uniformidade dos dados na instituição. Essas instruções podem ser chamadas de requisitos informacionais, que configuram condições e atributos que as informações geradas pela instituição devem ter. Esses requisitos serão atendidos tanto por meio da estruturação dos sistemas de informação quanto pela gestão e governança dos metadados, dados e informações. 0 uso desse manual de instruções representado na matriz de metadados, consequentemente, contribui para a qualidade dos dados e beneficia a governança de dados:

A menos que os padrões de dados corporativos sejam estabelecidos e aplicados, haverá diferenças na forma como os dados são definidos e criados em diferentes áreas. Por exemplo, considere algo aparentemente simples como um Número de Segurança Social (Social Security Number - SSN), um identificador americano para indivíduos. Se uma aplicação captura o SSN como um valor numérico e outro a captura em um campo de texto, os dados do SSN serão formatados de maneira diferente. Isso pode resultar em problemas como a eliminação de zeros à esquerda nos SSNs. Diferenças de formatação, diferenças na granularidade dos dados e diferenças sobre quais atributos são obrigatórios para capturar - todas essas diferenças apresentam obstáculos à integração de dados de diversas aplicações. Os obstáculos à integração limitam o valor que uma organização pode obter com seus dados. (ENAP, 2019)

Dependendo do tamanho da instituição e do volume de processos de negócio, recomendase que a matriz de metadados seja elaborada de forma automatizada em um repositório de dados e informações. Tal implementação permite que os metadados de negócio identificados nos processos e registrados nos documentos de AI possuam uma fonte de recuperação única, que pode estar disponível para consulta de toda a instituição e com variados níveis de acesso. 
Brandt (2020), em sua tese de doutorado, desenvolveu um repositório de metadados de negócios ${ }^{4}$ a partir de dados coletados em documentos da Câmara dos Deputados, com o objetivo de identificar metadados de negócio para a informação legislativa. Tais dados estão disponíveis em um dataset e 0 processo de coleta está relatado em um artigo de dados (BRANDT; VID0TTI, 2020). Além disso, Brandt (2020) apresentou um modelo conceitual que interliga três entidades principais da metodologia de Arquitetura da Informação para Processos de Negócio, por meio das coleções que possuem metadados customizáveis: "Processos de trabalho", "Documentos" e "Metadados de negócio", conforme Figura 5.

Figura 5 - Modelo conceitual de repositório de metadados

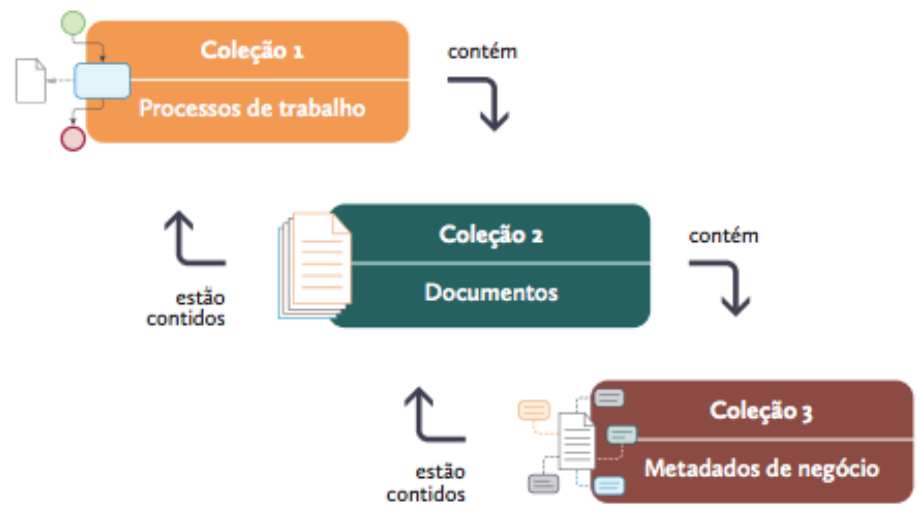

Fonte: BRANDT (2020, p. 168)

A partir da matriz de metadados, é possível elaborar-se outro entregável específico para a governança de dados. Nessa etapa, os mesmos metadados de negócio identificados, ou um extrato dos mais importantes para o negócio e que precisam de uma governança mais atenta, devem ser incluídos em outra tabela, referente à Matriz de Governança. Na tabela, para cada metadado de negócio devem ser identificadas áreas de negócio que compõem a gestão dos dados gerados a partir desses metadados de negócio.

0 entregável funciona como uma versão da matriz RACI (Responsible, Accountable, Consulted e Informed) para gestão de projetos do Project Management Institute:

Matriz de responsabilidade é uma tabela que mostra os recursos do projeto alocados a cada pacote de trabalho. É usada para ilustrar as conexões entre os pacotes de trabalho ou atividades e os membros da equipe do projeto. [...] 0 formato matricial mostra todas as atividades associadas a uma pessoa e todas as pessoas associadas a uma atividade. Isso também

$4 \quad$ Disponível em: https:// marianabrandt.com.br/tese/blog/colecoes/ 
assegura que apenas uma pessoa seja responsável por cada tarefa para evitar confusão sobre quem, em última análise, está encarregado ou tem autoridade sobre o trabalho. Um exemplo de MR é um gráfico RACl (Responsável pela execução, responsável pela aprovação, é consultado e informado) [...] (PROJECT MANAGEMENT INSTITUTE, 2014, p. 254)

Para cada uma das áreas de negócio identificadas, atribui-se um papel de gestão: gestor do dado, responsável pela atualização, curador de dado, responsável pela origem do dado, entre outros que sejam considerados necessários pela governança de dados da instituição. Como exemplo, temos a estrutura de Governança do Banco Central do Brasil definida da seguinte forma (BRASIL, 2016):

Art. $5^{\circ} \mathrm{A}$ estrutura da Governança da Informação visa a assegurar a execução das melhores práticas de gestão e é composta por:

I - Comitê de Governança da Informação, que prevê um Subcomitê de Transparência e Dados Abertos;

II - Conselho de Curadores;

III - Curadores de Informações, que abrangem unidades curadoras de informações e agentes de curadoria;

IV - Escritório de Governança da Informação;

V - Auditoria de Observância.

0 entregável de AIPN para a governança pode ser representado conforme 0 quadro 2:

Quadro 2 - Matriz de Governança

\begin{tabular}{|c|c|c|c|c|c|}
\hline \multicolumn{6}{|l|}{ Processo de negócio: } \\
\hline Metadado & UA1 & UA2 & UA3 & Al & TI \\
\hline Metadado 1 & I & GD, I & GM & I, R & $\mathrm{I}, \mathrm{R}$ \\
\hline Metadado 2 & GM, GD & $\mathrm{I}, \mathrm{R}$ & C & I, R & $\mathrm{I}, \mathrm{R}$ \\
\hline Metadado 3 & GM & C, GD & I & I, R & $\mathrm{I}, \mathrm{R}$ \\
\hline Metadado n & C & I & GD, I & I, R & $\mathrm{I}, \mathrm{R}$ \\
\hline \multicolumn{6}{|c|}{ UA: Unidade administrativa } \\
\hline \multicolumn{6}{|c|}{ Al: Unidade responsável pela Arquitetura da Informação } \\
\hline \multicolumn{6}{|c|}{ TI: Unidade responsável pela Tecnologia da Informação/ Informática/ sistemas de informação } \\
\hline \multicolumn{6}{|c|}{ R: Responsável por execução de tarefa relacionada ao metadado de negócio } \\
\hline \multicolumn{6}{|l|}{ GD: Gestor do Dado } \\
\hline \multicolumn{6}{|l|}{ GM: Gestor do metadado } \\
\hline \multicolumn{6}{|l|}{ I: deve ser informado } \\
\hline C: deve ser consultado & & & & & \\
\hline
\end{tabular}

Fonte: Autoria própria 
No caso do Banco Central, conforme visto, no lugar de unidades administrativas (UA) seriam indicados os Curadores de Informação (Unidades curadoras de informação e agentes de curadoria) que são definidos pela política de governança da instituição (BRASIL, 2016).

Outros entregáveis podem ser gerados a partir dos citados anteriormente, como requisitos de recuperação da informação para buscas e relatórios gerenciais, controles de restrição de acesso e gestão arquivística. Destacamos neste artigo as etapas e os entregáveis gerados que são mais relacionados à governança de dados e essenciais para qualquer estrutura de Arquitetura da Informação para Processos de Negócio.

\section{CONSIDERAÇÕES FINAIS}

A necessidade de governança dos dados das instituições é cada vez maior e deve ser implementada em conjunto com práticas de gestão de dados e informações. É essencial que as áreas de negócio estejam cientes e sensibilizadas para a importância da gestão de suas informações. Essa gestão faz parte de uma instância maior de governança de dados, a qual não depende apenas das tecnologias e de seus sistemas de informação.

A Arquitetura da Informação para Processos de Negócio possui como principal elemento a gestão dos metadados de negócio e configura um caminho para a gestão de dados e informações dos processos e, consequentemente, para a governança de dados. "As organizações que não gerenciam bem seus dados geralmente não gerenciam seus metadados. A resposta para esse desafio é que 0 gerenciamento de metadados geralmente fornece um ponto de partida para melhorias no gerenciamento de dados em geral" (ENAP, 2019).

Por isso, entende-se que a Al identificada nos processos de negócio deve ser o ponto de partida para a construção dos sistemas de informação que dão suporte ao negócio para, assim, fornecer insumos para a gestão dos dados e informações, bem como a governança de dados por meio de seus entregáveis.

As documentações geradas e os entregáveis da Arquitetura da Informação para Processos de Negócios são verdadeiros ativos para a instituição, pois se configuram fontes essenciais nas práticas de gestão e governança com o intuito de fornecer orientações claras e objetivas sobre o funcionamento dos metadados, o processamento dos dados e o tratamento das informações. 


\section{FINANCIAMENTO}

Conselho Nacional de Desenvolvimento Científico e Tecnológico (CNPq) - Bolsa Produtividade em Pesquisa - 311936/2016-4

\section{REFERÊNCIAS}

BALDAM, R. L. et al. Gerenciamento de processos de negócio: BPM - business process management. 2. ed. São Paulo: Érica, 2007.

BRANDT, M. B. Modelagem da informação legislativa: arquitetura da informação para o processo legislativo brasileiro. 2020. 266 p. Tese. (Doutorado em Ciência da Informação) — Faculdade de Filosofia e Ciências, Universidade Estadual Paulista (Unesp), Marília, SP. Disponível em: https:// repositorio.unesp.br/handle/11449/191740. Acesso em: 10 jun. 2020.

BRANDT, M.B.; VIDOTTI, S. A.B.G. Dados de pesquisa em informação legislativa. Encontros Bibli: revista eletrônica de Biblioteconomia e Ciência da Informação, Florianópolis, v. 25, p. 01-14, 2020. Universidade Federal de Santa Catarina. ISSN 1518-2924. DOI: https://doi.org/10.5007/15182924.2020.e72208

BRASIL. Banco Central do Brasil. PORTARIA N 90.187, DE 17 DE AGOSTO DE 2016. Divulga a Política de Governança da Informação do Banco Central do Brasil. 2016.

BRASIL. Ministério do Planejamento, Orçamento e Gestão. Secretaria de Tecnologia da Informação. PORTARIA N ${ }^{\circ}$ 58, DE 23 DE DEZEMBRO DE 2016. Dispõe sobre procedimentos complementares para o compartilhamento de bases dedados oficiais entre órgãos e entidades da administração pública federal direta e indireta e as demais entidades controladas direta ou indiretamente pela União. 2016A.

BRASIL. Comitê Central de Governança de Dados. Guia de boas práticas Lei Geral de Proteção de Dados (LGPD). Gov.br, 2020. Disponível em: https://www.gov.br/governodigital/pt-br/governanca-dedados/guia-Igpd.pdf. Acesso em: 05 nov. 2020.

CHOO, C. W. A Organização do Conhecimento. 2. ed. São Paulo: Senac, 2006.

DAN SCHUR, R. A emergência da governança da informação. GV-executivo, Rio de Janeiro, v. 17, n. 2, p. 25-29, 2018.

DATA GOVERNANCE INSTITUTE (DGI). Definitions of Data Governance. DGI. 2017. Disponível em: http://www.datagovernance.com/adg_data_governance_definition/. Acesso em: 20 jun. 2020.

DAVENPORT, T. H.; BEERS, M. C. Managing information about processes. JMIS - Journal of Management Information Systems; v. 12, n. 1; p. 57-80, 1995.

DIAS, G. A.; VIDOTTI, S. A. B. G. 0 direito da propriedade intelectual: relações com os entregáveis da Arquitetura da Informação. Perspectivas em Gestão \& Conhecimento, v.1, p.73-85. Disponível em: http://periodicos. ufpb.br/ojs2/index.php/pgc/article/ view/10825/6100. Acesso em: 18 jun. 2020. 
ENAP. Escola Nacional de Administração Pública. Governança de Dados [curso online]. Brasília, 2019. Disponível em: https://www.escolavirtual.gov.br/curso/270. Acesso em: 20 jul. 2020.

ESPINDOLA, P. et al. Governança de dados aplicada à ciência da informação: análise de um sistema de dados científicos para a área da saúde. Revista Digital de Biblioteconomia \& Ciência da Informação, v. 16, n. 3, p. 274-298, 2018. DOI: http://dx.doi.org/10.20396/rdbci.v16i3.8651080. Acesso em: 22 jun. 2020.

FORSOS, M. Why data governance and business process management must be linked. Erwin expert blog. 2018. Disponível em: https://erwin.com/blog/linking-data-governance-and-businessprocess-management/. Acesso em: 22 jun. 2020.

GARTNER. IT Glossary: Information Governance. 2018. Disponível em: https://www.gart- ner.com/itglossary/information-governance. acesso em 28 nov. 2018.

GONÇALVES, J. E. L. As empresas são grandes coleções de processos. RAE - Revista de Administração de Empresas, v. 40, n. 1, p. 6-19, 2000.

MIRANDA, S. V. A gestão da informação e a modelagem de processos. Revista do Serviço Público. Brasília, v. 61, n.1, p. 97-112 jan/mar 2010.

PROJECT MANAGEMENT INSTITUTE. Um guia do conhecimento em gerenciamento de projetos: guia PMBOK. 5. ed., 3. tiragem. São Paulo: Saraiva, 2014.

TRIBUNAL DE CONTAS DA UNIÃO. Fundamentos de governança. Brasília, 2019. Disponível em: https://portal.tcu.gov.br/governanca/governancapublica/governanca-no-setor-publico /. Acesso em: 20 jun. 2020. 